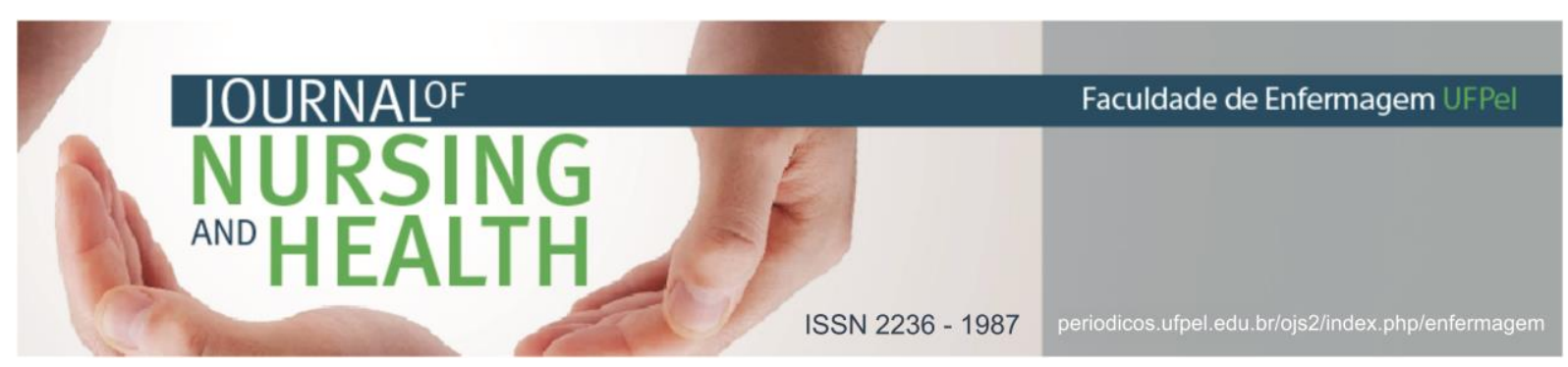

ENTREVISTA NARRATIVA

\title{
Ouvidores de vozes no Brasil: as sementes do movimento
}

\author{
Voice hearers in Brazil: the seeds of the movement
}

\section{Oyentes de vocês en Brasil: las semil las del movimiento}

Oliveira, Michele Mandagará de ${ }^{1}$; Pereira, Gabriela Botelho²; Ramos, Camila Irigonhé3; Borges, Carla Luciane dos Santos ${ }^{4}$; Santos, Diego Elias Rodrigues dos $^{5}$

Como citar este artigo: Oliveira MM, Pereira GB, Ramos $\mathrm{Cl}$, Borges CLS, Santos DER. Ouvidores de vozes no Brasil: as sementes do movimento. J. nurs. health. 2018;8(n.esp.):e188424

Palavras-chave: Saúde mental; Ouvidores de vozes; Narrativas.

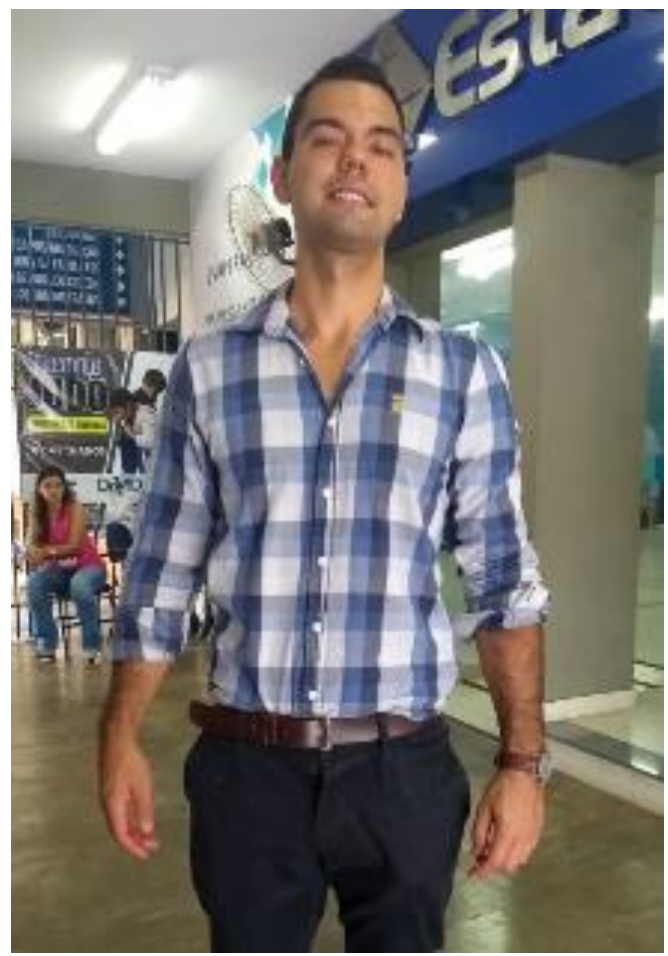

\section{APRESENTAÇÃO}

0 presente artigo é a narrativa de Pablo a respeito do surgimento do movimento Ouvidores de Vozes no Brasil, conforme sua perspectiva. A narrativa revela-se um importante instrumento para se realizar investigações qualitativas, dispondo para os pesquisadores dados capazes de produzir conhecimento científico compromissado com a apreensão fidedigna dos relatos e a originalidade dos dados apresentados, uma vez que permitem combinar histórias de vida a contextos sócio-históricos, viabilizando a compreensão dos sentidos que produzem mudanças nas crenças e valores que motivam as ações dos informantes. ${ }^{1}$

\footnotetext{
1 Enfermeira. Doutora em Enfermagem. Universidade Federal de Pelotas (UFPEL). E-mail: mandagara@hotmail.com http://orcid.org/0000-0003-1363-7206

2 Enfermeira. Mestre em Ciências. Universidade Federal de Pelotas (UFPEL). E-mail: gabrielabotelhopereira@gmail.com http://orcid.org/000-0002-9964-6586

3 Nutricionista. Mestre em Nutrição e Alimentos. Universidade Federal de Pelotas (UFPEL). E-mail: mila85@gmail.com http://orcid.org/0000-0001-8593-1397

4 Enfermeira. Mestre em Ciências. Universidade Federal de Pelotas (UFPEL). E-mail: c.l.borges@hotmail.com https: / / orcid.org/0000-0003-0535-8768

5 Enfermeiro. Especialista em Saúde Mental e Coletiva. Universidade Federal de Pelotas (UFPEL). E-mail: pcmdiego@yahoo.com.br http://orcid: 0000-0002-2711-0803
} 


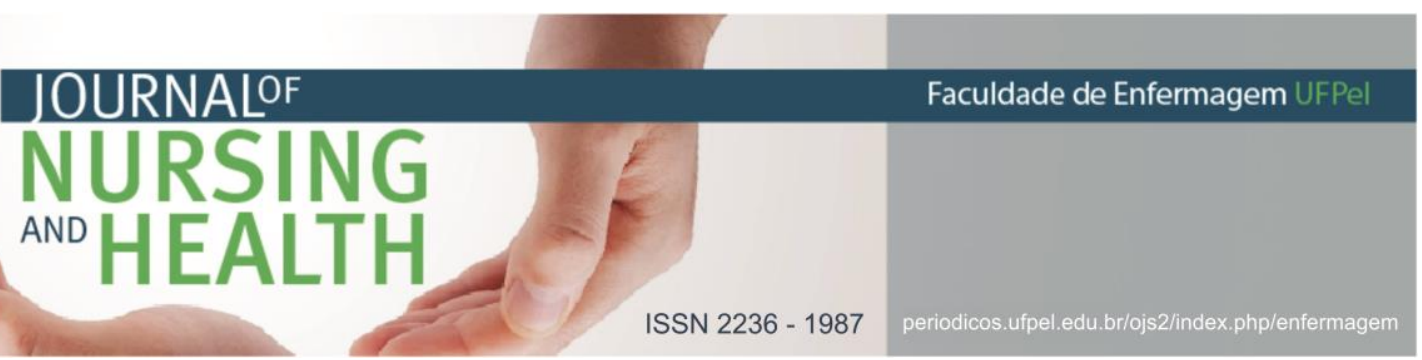

Contato com a saúde mental e ouvidores de vozes

O meu nome é Pablo, sou formado em uma área que não tem nada a ver com saúde, muito menos com saúde mental, sou formado em administração, com pós em finanças. Sou formado no Mackenzie.

Desde criança a saúde mental está presente na minha vida, porque minha mãe é professora da Universidade Estadual Paulista (UNESP), e sempre tive contato com essa área. O contato acontecia em conversas entre nós, assim como com outras pessoas da saúde mental, principalmente no período em que estive junto com minha mãe em Trieste por três meses enquanto ela fazia pósdoutorado e eu acabava um intercâmbio em Dublin. Nesse momento pude entender mais o que era saúde mental e o processo de desinstitucionalização. Retornei ao Brasil em 2012 e terminei a faculdade em 2014.

Neste período minha mãe estava organizando, juntamente com a professora Clarissa da Universidade de São Paulo (USP) de Ribeirão, a primeira escola Franco Basaglia em Campinas. Até então o tema ouvidores de vozes era muito restrito a um pequeno grupo do Rio de Janeiro, da Universidade Federal do Rio de Janeiro (UFRJ), com a Professora Erotildes Maria Leal e com o Professor Octávio Domont de Serpa Júnior. O Paul Baker foi um dos participantes desse Fórum, ele veio por acaso, porque John Stacy que era um dos convidados o trouxe com ele. Ele achou importante que o Paul Baker viesse, tanto que pagou passagem e hospedagem para ele. O Paul Baker falou durante uma hora sobre o tema ouvidores de vozes e todo mundo ficou apaixonado pelo jeito que ele falou e pelo tema, pensaram: "Nossa...o que é isso!?" Como os demais palestrantes, o Roberto Mezzina de Trieste, John Jacke, foram para Foz do Iguaçu, e Paul Baker ainda ficaria por quatro ou cinco dias em São Paulo, então o convidei para ficar na minha casa. Foi quando começamos a conversar e trocar ideias, foi quando o Paul Baker sugeriu que seria muito legal fazer um workshop sobre o tema ouvidores de vozes, já que tinha visto que as pessoas haviam gostado, mas ainda tinham pouco conhecimento mais aprofundado sobre o tema.

\section{Articulações para disseminação do tema ouvidores de vozes}

\section{Workshop}

Em 2014, o Paul Baker e eu começamos os workshops, em Marília, em Campinas e no Rio de Janeiro. E, também um Fórum em Belém. Nestes a procura foi bem pequena, em Campinas acho que teve uns 15 participantes, em Marília uns 19, $e$ no Rio de Janeiro, que teve um pouco mais, foi uns 45. Na mesma época, o Paul Baker, que é muito amigo do Marius Romme, o convidou para fazer esses workshops, achando que seria muito importante sua participação. Marius Romme passava primavera e o verão na Europa, Holanda, e de outubro a março na sua casa em Curaçao. Paul Baker disse a ele que já que estava perto, em 


\section{NURSING \\ AND

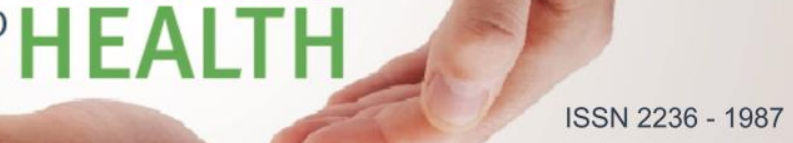

Curaçao, viesse para o Brasil. Foi então que Marius Romme participou do workshop em Campinas, do Fórum em Belém, e no Rio de Janeiro, quando foi junto com o Professor Octávio Serpa Júnior conversar com os alunos, quando esse tema começou a ser colocado em discussão.

\section{Grupo}

Além do Marius Romme, também participaram em Campinas o Leonardo Duarte Bastos e o Eduardo Augusto Leão de Ribeirão Preto, que começaram a formar o grupo. Aí começou a surgir o Grupo no Rio de Janeiro, até então ele não estava funcionando e foi retomado. Também iniciou a formação do grupo de ouvidores de vozes em Campinas, dentro da comunidade e o grupo de ouvidores de vozes de Ribeirão Preto, dentro do Centro de Atenção Psicossocial (CAPS). A organização de grupos de autoajuda/ajuda mútua compostos por ouvidores de vozes possibilita a criação de espaços coletivos de compartilhamento dessas experiências, de tal forma que apostam na capacidade de produzir uma melhor convivência com as vozes, a partir do compartilhamento de vivências, informações e estratégias de enfrentamento. ${ }^{2}$

\section{Fóruns}

Então, em 2016, realizamos o Fórum em João Pessoa, Brasília, Recife e novamente Rio de Janeiro. Também Porto Alegre e Curitiba. Foram seis fóruns. Em todas as cidades o tema central foi Ouvidores de Vozes, e todos que assistiam ficavam apaixonados, achando o tema muito interessante. $E$ o mais legal, que mais chamava atenção das pessoas é que poderia ser colocado em prática, diferente de um open dialogue, que também é legal, interessante. No open dialogue, precisa uma mudança de mentalidade de todos, da equipe, do poder público, que compreendam, que mudem isso, então é um pouco mais complicado. Já os ouvidores de vozes não é uma coisa que qualquer pessoa pode colocar em prática, é isso que chamou a atenção das pessoas, pode ser feito em qualquer lugar, pode ser feito na sua própria casa.

\section{E esse movimento começou a crescer}

E esse movimento começou a crescer, em 2017, nós realizamos oito fóruns e um congresso. Conversando com o Paul Baker, colocamos uma meta de 10 grupos, formar 10 grupos de ouvidores de vozes no Brasil. No começo estava muito fraco, eu falei pro Paul Baker que já não sabia mais... Fiz um e-book de como é o The International Hearing Voices Network (INTERVOICE) e de como montar um grupo de ouvidores de vozes e não estava andando muito bem, como eu imaginei que seria. 0 grupo INTERVOICE foi criado em 2009, no Facebook (http://www. facebook.com/groups/ Intervoice/). O conteúdo das postagens é de acesso público, de usuários já cadastrados no Facebook. Os participantes podem postar comentários, fotos, vídeos e arquivos, sendo um fórum para discussões, apoio, conselhos e informação sobre escutar vozes, para qualquer 


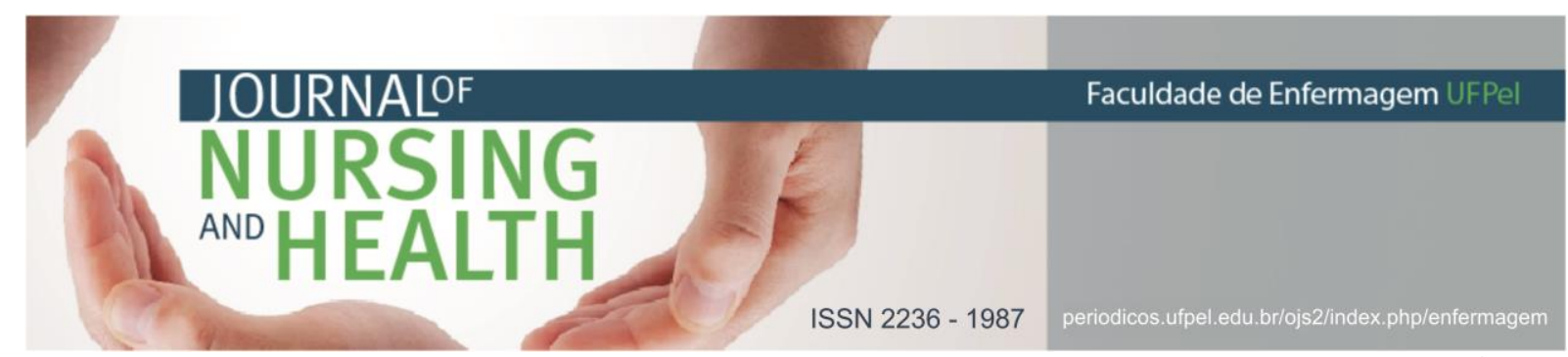

um com interesse (ouvidores de vozes, familiares, amigos e profissionais). ${ }^{3}$ Que as pessoas iriam incorporar a ideia mais facilmente, colocar em prática, mas muitos acham bem legal, e fica só na teoria, não coloca em prática. Falei com o Paul Baker e ele disse que poderíamos fazer um Congresso Nacional de Ouvidores de Vozes, falando só sobre esse tema, colocando esse tema em voga, onde mais pessoas iriam se interessar e despertar para que essas pessoas colocassem em prática a formação dos grupos. Paul Baker ainda disse que uma pessoa sensacional para falar seria o Ron Coleman, porque tem uma experiência de ser ouvidor, de ter participado, de ter vivido em um hospital psiquiátrico e conseguiu autonomia, ainda da importância dos grupos na vida dele e o seu jeito de falar. Foi onde começou o Congresso, eu falei com o pessoal do Rio de Janeiro, eles acharam boa a ideia e aceitaram fazer. Então falei com o Henrique, Leonardo e Eduardo Augusto Leão de Ribeirão Preto, quando iniciou a articulação para a formação do Congresso. E mesmo antes do Congresso, estamos vendo que já tem mais grupos se formando, e acho que essa meta de 10 grupos formados neste ano vai ser atingida, já são seis ou sete grupos em formação, mais uns quatro grupos que estão em prática. Então acho que é essa a história.

\section{REFERÊNCIAS}

1 Muylaert C, Sarubbi Jr V, Gallo P, Neto M, Reis A. Entrevistas narrativas: um importante recurso em pesquisa qualitativa. Rev esc enferm USP [Internet]. 2014 [acesso em 2018 set 10];48(spe2):184-9. Disponível em: http://www.scielo.br/pdf/reeusp/v48nspe2/pt_0080-6234-reeusp-48-nspe200184.pdf

2 Kantorski LP, Antonacci MH, Andrade APM, Cardano M, Minelli M. Grupos de ouvidores de vozes: estratégias e enfrentamentos. Saúde debate [Internet]. 2017 [acesso em 2018 set 10];41(115):1143-55. Disponível em: http: / / www.scielo.br/scielo.php?script=sci_arttext\&pid=S0103-11042017000401143

3 Barros OC, Serpa Júnior OD. Hearing voices: a study on exchanges of experiences in a virtual environment. Interface (Botucatu, online) [Internet]. 2014 [acesso em 2018 set 10]; 18(50):557-69. http: / / www.scielo.br/scielo.php?script=sci_arttext\&pid=S1414-32832014000300557

Data de publicação: 19/09/2018 